\title{
Financial Technology Promoting Healthy Lifestyle and Community Development
}

\author{
Muhammad Anshari ${ }^{1}$, Mohammad Nabil Almunawar ${ }^{2}$, Masairol Masri ${ }^{3}$ \\ Universiti Brunei Darussalam, School of Business \& Economic ${ }^{1,2,3}$ \\ \{anshari.ai@ubd.edu.bn¹, nabil.almunawar@ubd.edu.bn², masairol.masri@ubd.edu.bn ${ }^{3}$ \}
}

\begin{abstract}
The paper proposes a Financial Technology (FinTech) as a platform to encourage people who are physically active to participate in raising funds for social work activities and at the same time generate income for the participants. The research is empirical evidence based on a mixed methodology approach to assessing people's perspectives from the general public, a charity organization, and business organizations. While, FinTech as a platform will be able to promote a healthy lifestyle allowing people to collect their distance in kilometers by either walking, running or cycling then converting them into a reward point. The platform provides more meaning to every distance that can impact physically, socially, and financially to promote a healthy society.
\end{abstract}

Keywords: Physical Exercise; Social Work; Financial Technology; Digital Wallet

\section{Introduction}

Smartphone has become our necessity that it has changed the way we do things in such a way that is more efficient and cost-effective. One major change is that most countries have moved from physical cash and have evolved into a cashless society to make payments in their daily lives. With the input of a couple of numbers, a transaction can be made and a bill settled without the individual even stepping out of the comfort of their homes.

The research is on the feasibility of an application (Apps) that encourages someone who are physically active to participate in raising funds for charities and at the same time get income from their physical exercise. The platform promotes a channel for charities to consistently receive public funding that are approved by the government. Additionally, it also creates an opportunity for corporations to have a joint effort as part of their corporate social responsibility (CSR) and will be acknowledged as supporters of the cause.

The latest generation consisting mostly of Generation Y, the 'millennials' and the future Generation $Z$ who are smart, tech savvy and exposed with technology during their younger age. With Internet of things, processes are becoming easier, faster, thus increasing the efficiency and effectiveness of a system. This is where almost everything can be done within the reach of one fingertip using the smartphones and tablets [1].

It connects public, sponsors (corporations and marketing organizations), merchants, and charity organizations together into a single platform. People can make donations based on the distance they have covered (collect their distance in kilometers by either walking, running or 
cycling). The distance is converted into points of rewards. On the other hand, the sponsors will fund the user's donations according to the collected points in kilometers. The funds raised will be channeled to the charities organization. In addition, some portions of collected points can be converted into reward bonus that can be cashed in or vouchers for commerce transactions at partnering merchants. Partnering merchants will share benefits from any transactions made to the platform for funding. The platform will act also as Financial Technology (FinTech) especially digital payment for the users [2].

Since there are not many research have been conducted in the domain of social work, health activities coined with FinTech development, then this research might fill the gap of each domain of knowledge. The aim of the research is to look into the feasibility of developing a platform that will help ease the process of making a donation. The study was developed using mixed methods by collecting and analyzing data from the potential stakeholders of Spur and to develop Spur's prototype. The model promises an effective means to engage corporation for corporate social responsibility (CSR) and be acknowledged supporters of the cause, charity organization to gain the funding easier, general public to promote healthy lifestyle as well as financial benefits. Spur is Fintech enabled platform that encourages general public a healthy lifestyle allowing people to collect and convert their distance in kilometers by either walking, running or cycling and record their daily movement hence, giving them more meaning to every distance they have covered physically and socially impact to the society.

\section{Literature Review}

\subsection{Social Work and Financial Technology}

Non-governmental organizations which claimed to be private organizations are voluntary and open associations of individuals outside the formal setting, where profit and engaging in political activities are not their primary objectives [3]. NGOs as 'formal (professionalized) independent societal organizations whose primary aim is to promote common goals at the national or the international level' [4].

IoT, internet and growth of mobile and communication had accelerate the changes in volunteering platform giving the rises in online volunteering. An online volunteering model can be seen from two aspects where the first aspect is utilizing the internet as a medium to assist partly in volunteering activities. Whereby, the Internet serves to organize the creation of the volunteer project and act as a medium to run it, while the volunteering activities itself takes place offline [5].

The existence of the Internet has influenced a lot of change in people's lives and in relation to the ever growing, ever advancement of technologies, it forces people to move forward with it. The Internet brings about positive and negative impacts where, in this report, will talk about its positive impacts [6]. Few of the positive impacts are such that it made sources or information to be easily accessed and it made transactions a lot easier such as mobile banking. There is a constant change in technology in this day and age where these changes bring economic and social consequences on a daily basis [7]. In the future, there will come a time in the future where people will have less time to prepare themselves for the fast-changing pace of technologies [8].

With the growth of the Internet, a wide range of ICT have transformed social relationships and social work, and the dissemination of information [9]. It is argued that online 
relationships can have properties of intimacy, richness, and liberation that rival or exceed offline relationships, as online relationships tend to be based more on mutual interest rather than physical proximity [10]. It has been suggested that information and communication technologies (ICT) can and do play a number of roles in social work activities.

Furthermore, Internet of Things had brought an enormous and impactful changes to the daily life since the emergence of information system and internet connectivity around the world. IoT as the one that create intelligent, invisible network fabric that can be sensed, controlled and programmed. He further explained that IoT employ embedded technology which allow direct and indirect communication over the Internet [11].

Furthermore, Financial Technology (FinTech) is one of the most cutting edge technology ever created in the 21 st century. The scope of FinTech is very broad where it covers many financial activities. There are new capabilities and modes in insurance, e-payment, money transaction, digital security, investment, data analysis, Peer-to-Peer lending, crowdfunding and etc. These product provide a positive customer experience and all user friendly while also reducing costs. FinTech has existed for many years and there is an enormous gap from when our society started establishing the system. Many organizations are investing in FinTech can deliver additional value or even disruptive to the existing financial institution [12].

Utilizing FinTech for social and financial empowerment for expanding network to ensure good access of potential customers to the e-financial services and also ensuring high quality of services in terms of safety with reasonable cost to gain more trusts and satisfactions of customers.

\subsection{Context of Study}

Listed in Top 50 Countries with Highest Internet Penetration Rates, Brunei Darussalam is Brunei ranked at the 42 nd place with $75.4 \%$ of Internet penetration. Social media penetration, Brunei is currently ranked the 4 th highest with $95 \%(410,000)$ active social media users [ $[13$, 20]. From this statistics, it shows that Brunei has a high Internet and social media penetration which can support as to why Spur is feasible in Brunei Darussalam. The mobile penetration in Brunei Darussalam is around $125.5 \%$ in 2016 where there is also a rise in mobile broadband penetration of $118.7 \%$ in the first quarter of 2017 compared to $115.7 \%$ in 2016 and $93.1 \%$ in 2015. The top applications used in Brunei are WhatsApp (97\%), Facebook (92\%), Instagram (87\%), Twitter (49\%), Skype (46\%) and Telegram (35\%) as of 2017 [14].

Moreover, it was revealed that Bruneians used the social media and messaging app for sharing information and opinions $(65 \%)$, sharing photos $(64 \%)$, video sharing $(53 \%)$, online shopping (52\%), making new friends (37\%), business-related activities $(25 \%)$ and marketing $(17 \%)$ [14]. This shows that Spur can make full use of these habits by integrating it into the design of the Apps.

According to the United States of America CIA Factbook, as of 2015, the literacy rate of Brunei was $96 \%$ of its total population. Considering the rate of internet penetration and popularity of mobile apps in Brunei, coupled with a high literacy rate in the country, there is an opportunity for a charity Apps to succeed. A high literacy rate translates to a high number of people capable of utilising mobile devices and the probability of using mobile Apps. According to AITI Household ICT Survey (2016), mobile phones are the top most used devices in a household (99\%), followed by laptops (93\%) and tablets (62\%) [15].

In term of demographic characteristics, the population of Brunei is approximately around 443, 600 people, where $72 \%$ are of the working population [16]. Additionally, based on a survey conducted by Ministry of Health of Brunei in 2016, the four leading causes of deaths in 
Brunei are cancer $(21.6 \%)$, heart diseases $(12.9 \%)$, diabetes $(9.1 \%)$ and cerebrovascular diseases $(7.5 \%)$. However, in recent years, heart diseases have become the leading cause of death among Bruneians [17]. On the relationship of heart diseases and physical activity, it was founded that people who do physical activities on a regular basis have a lower risk of getting coronary heart diseases in comparison to those who are not active $[18,19]$. Besides this, the government have also been making the initiatives to increase awareness among the population to do physical activities in order to prevent such diseases. An example of such initiative is "Bandarku Ceria (my happy city) "initiative which is being carried out every Sunday morning, in the capital. Activities being carried out on the day includes jogging and cycling.

In the past few years, due to the efforts that were taken by the government to increase awareness of living a healthy lifestyle, Bruneians have become more active than ever. Health and fitness centers are budding all over the country, offering a wide range of activities for the general public. Among the trending physical activities are CrossFit, boot camps, spinning, weightlifting, martial arts (such as Muay Thai and kickboxing), yoga, piloxing and cycling. Bruneians are currently very active in participating in fitness events such as "January: Fun to be fit" event carried out by one of the shopping centers as well as "She runs" which was an event conducted by one of the most renowned fitness center in Brunei to promote breast cancer awareness, in collaboration with the Ministry of Health and events carried out by event organizers such as "The Alpha Challenge" and "Brunei Marathon Swim".

\section{Methodology}

The study deployed mixed methodology for data collection where the instruments used are; interviews and surveys. Interviews were conducted with one of the leading charity organization in the country on October 7th, 2018 whereas an interview was conducted with corporation's representative on October 10th, 2018 and October 18th, 2018. On the other hand, surveys were given out through Google Forms where a link was shared to the general public via WhatsApp and on Facebook. There are two sections in the survey where the first section contains a total of 8 general questions and in the second section containing the paper prototype and questions regarding the public's impression on its aesthetics and its userfriendliness. A total of 215 respondents were gathered and the survey was closed by October 31 st, 2018 .

\section{Results and Discussions}

\subsection{Charaty Organization Perspective}

In the interview, the representative was first introduced to social charity App and were later on asked regarding its feasibility and how it will be able to help NGOs. According to respondent, it will help charity organization to cut their costs in terms of fundraising events. Charity organization held fundraising events such as garage sales, selling cookies and through their retail shop where the garage sales are held as often as every three months whereas other fundraising activities vary from once every three months or once every six months. Hence, through this app, it will help them to reduce the frequency of their fundraising events which usually have high overhead costs. Additionally, respondent mentioned regarding charity organization opening an account in local banks to make donations made easier, however, the 
donations through the account is very unstable as banks charged the person processing fee or transfer charges when they make donations through bank transfer and that made it inefficient. Another reason as to why cutting costs are important due to the unstable monthly donations they receive that they had experience "dry season" where they did not get any monetary support for a few months.

Charity organization was very enthusiastic about the idea of a social charity app such as Spur to actually be realized as she mentioned that majority of the charity organizations in the country have not been able to penetrate the mass public thus, they are lacking in publicity though they are one of the most recognized charity organizations in the country. Respondent mentioned that with the existence of such app, it will also help charity organization to reduce their fundraising events.

Moreover, they will not face the difficulty in getting employees to help with the events as well as they sometimes cannot afford to hire extra help. Respondent also commented on what Spur could improve on such as adding other activities such as swimming, weight-lifting or CrossFit as there are a lot of people that are into those activities. Last but not least, respondent recommended for Spur to work on adding other ways to measure the donations aside from using kilometres (KM), she mentioned that using calories burnt can be a good idea as well.

\subsection{Corporate Perspective}

The other objectives of the research was to understand the standpoint of stakeholders of Spur, who are the potential users, charity organizations and prospective corporate sponsors. Among the companies that were approached for this study, only one corporation responded. According to the correspondent, the organization carries out CSR activities on the basis of three core pillars; Community, Education and Entrepreneurship. Activities revolving around this three topics have the opportunity to be chosen as part of their CSR activity. When asked about the frequency and whether the organization has allocated budget for CSR activities, it was revealed that the company does have annual budget allocated and that CSR activities are done mainly on a quarterly basis, with some CSR requirements that need to be achieved annually.

When asked regarding charity apps that corporation utilize to carry out their CSR activities, the respondent stated that the bank does not have any or have heard of any app that could assist them in any CSR activities. Therefore, according to the respondent, it would be feasible for such app like Spur, to be introduced into the users as most of the population owns a smartphone and due to the high internet penetration of the nation. Besides this, he also believes that an app such as Spur would be able to assist companies to ease it CSR activities. The respondent agreed that Spur would work in the country, adding that Spur will contribute greatly in encouraging and creating awareness among people to be more socially responsible.

\subsection{General Public Perspective}

Figure 1 shows the respondents' respond on "how often do you walk, jog, run or cycle?" and majority mentioned that it is as frequent as once a week, followed by daily and on the weekdays only whereas the rest is lower than $15 \%$ such as once every few months, weekends only, a few times a week and when they have free time. This indicates that majority people are somehow active in doing physical activities and are interested in living a healthy lifestyle. Furthermore, the question asks "howactive are you in a charity walk, jog, run or cycle?" and 
more than $75 \%$ of the total respondents are active while about $22 \%$ have never participated yet.
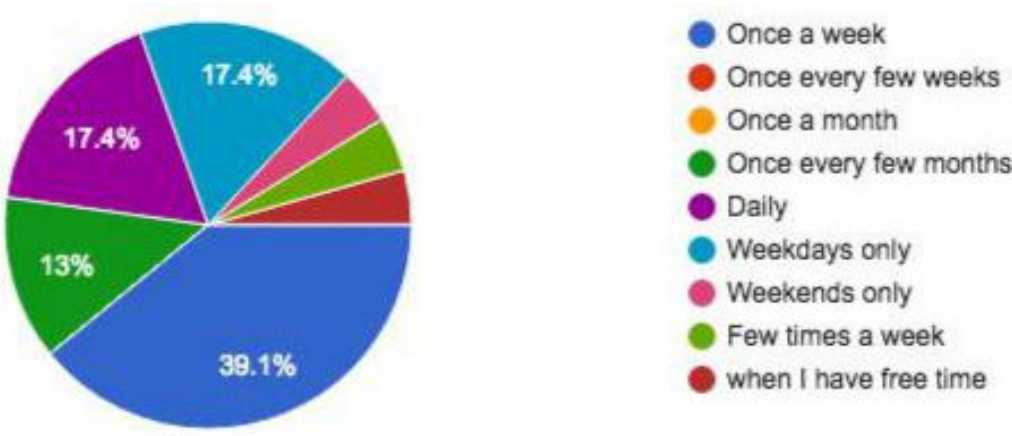

Fig. 1. Physical Activitty Frequency

Furthermore, the question reads "how often do you donate to charity organizations as an individual?". The keyword to this question is as an individual where only $9 \%$ of the respondents have never donated before and this actually supports the statement that majority of people in Brunei are philanthropic either due to the culture of helping others when an opportunity comes. The survey asked the respondents to list out the charities that they support and these are the names of NGOs that were mentioned (though most do not have any specific charity that they support); Pusat Ehsan, SMARTER Brunei, DANA, Brunei Darussalam AIDS Council (BDAC), Beach Bunch, LaunchGood and to any mosques.

Easy of making donation - "Do you think it is difficult to make donations here?" is the fifth question and about $70 \%$ mentioned that it is not as difficult. Though it may not be difficult, charity organizations still struggle from time to time as did not receive stable donations hence, the more reasons to develop Spur as what the respondent from charity organization mentioned, not all charity organizations have enough publicity to create awareness.

Motivation to donate - The respondents were then asked, "if you were able to make donations just by walking, jogging, running or cycling, would you be interested to participate?" most of the participants are most likely to do physical activities if the motivation is to donate.

Feasibility of Spur - When asked "do you think that an app that allows you to make donations by doing healthy activities is feasible? Explain",about $70 \%$ voted yes, $21.7 \%$ are unsure and about $9 \%$ mentioned that it is not workable. Their explanations as to why it will succeed are; public are active and philanthropist, a similar concept has been done however, without using any Apps, Apps is in trend, it is convenient, exercising is currently in trend and that this app is an interesting concept to some. On the other hand, the reason as to why they think it will not succeed are; they have doubts about the Apps as it is something new, they are unable to see how the platform will be able to retain its user and that these type of platform requires attractiveness as well.

As for the final question, the respondents were asked: "what are your expectations if you were to register on a social charity app mentioned above?".The respondent's answers are divided into three categories;

a. Platform: User-friendly, Easy accessibility, e-Payment features, Redeemable rewards -this will be Spur's customer retention strategy, Varieties of device compatibility, and Regular updates and troubleshooting 
b. Transparency: Activity and donation tracking, Notified when donations are received by NGOs, How the donations are used by the NGOs -- however, it would be difficult for anyone outside of the NGOs to get information or have control over this issue thus, this point is considered invalid.

c. Commitment: Makes people want to commit to using the app.

\subsection{Discussion}

A prototype is a platform draft design that combine the user's expectations where in this case, it is specially made for design and testing. The prototype is in the second section of the survey where firstly, it shows the public the paper prototype and then followed up with a few questions on its user-friendliness and color scheme. As for the user-friendliness, $59 \%$ of the respondents say it is good while $30 \%$ says it is fair and $13 \%$ mentioned that it is excellent. On the other hand, for the color scheme; $48 \%$ of the respondents think it is good, $48 \%$ think it is fair and $4 \%$ think it has a poor color scheme. Overall, $87 \%$ of the respondents are likely to register and use Spur.

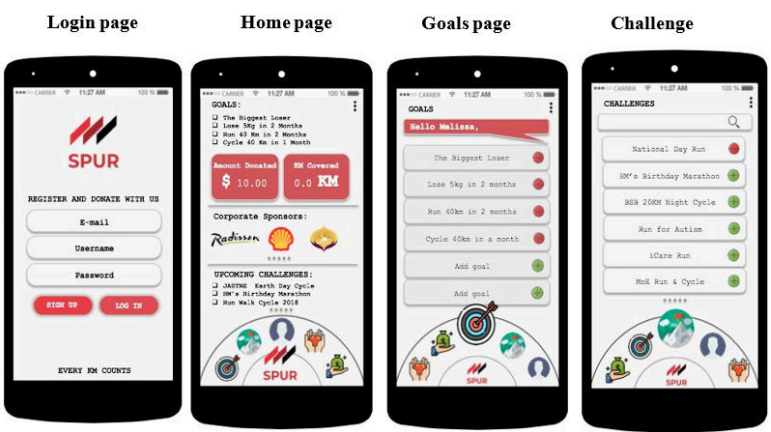

Fig. 2. Protopype Interface

After analyzing the findings from the survey as well as from the interviews, there are a few recommendations that can help in making Spur more attractive to its intended users. Below are Spur's prototype. Figure 2 shows login page, homepage, goals page and challenge page. Login page differ between users, charity organization, and corporations depending upon their role. Users are general public that takes part in physical exercise activities. Charity organizations require login to officially register into the platform to get funding. Corporations are sponsor that support program from their CSR. However, the platform also allows general publics to become sponsor from their personal charities. Homepage is the welcoming page once the user successfully login into the system. Goal page is personal page for each user that they can set and customize accordingly about their physical activities that they want to achieve. Challenge page is alert page containing physical events. It is push messaging services from Spur provider. It has more choices of challenges where Spur can even organize or create challenges that are attractive. 


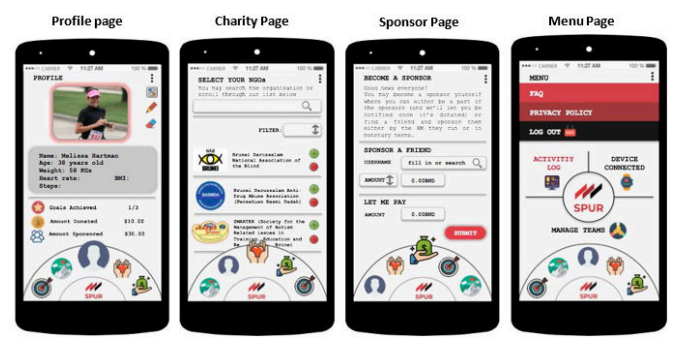

Fig. 3. Activity Pages

While, Figure 3 consists of profile page, menu page, charity page, and sponsor page. Charity page includes clips from the charity organization, where members of each organization could pitch their plans for its organization thoroughly in order to gain the trust and support of users or clips of what has been achieved with the donations they received. Profile page has social media enabled feature connecting the App to social media. Profile page also includes other activities/sports to the activity that can be detected, instead of just activities that calculate distance, perhaps it can be improved to detect calories burnt or energy consumption for particular activities. Sponsor page is where sponsors can donate and recognition and appreciation of the sponsors are displayed throughout push messaging services and social media promotion. Menu page is where the users are able to sync/connect with multiple smart devices such as a smartwatch or fitness band (i.e Fitbit, Jawbone).

Finally, the menu page consist of rewards that can be expected by users because Spur is also having Financial Technology (FinTech) feature where the physical activities are also converted to the points of rewards. Adding on the FinTech's features as a customer retention where the users can claim points or cash in the point or prizes such as vouchers or discounts in collaborating merchants [21]. These rewards can converted from the distance they have achieved or when they have achieved their goals [22].

Spur connects the users (general public), sponsors (corporations) and charity organizations. It enables the users to make donations based on the distance they have covered (collect their distance in kilometers by either walking, running or cycling). On the other hand, the sponsors will fund the user's donations according to the distance collected in kilometers. The funds raised will be channeled to the user's selected charities.

Due to the nature of the social charity app, users could accumulate the distance that they have covered and convert it into funds that would be donated to their chosen charities. These funds hail from participating sponsors, who are from various corporate organizations as well as private individuals. Hence, companies that are looking into consistently contributing back to the community will find it convenient to plan their CSR program via this app. Instead of only contributing to one particular cause, this app allows sponsors to distribute funds to multiple recipients. Consequently, Spur gives good causes to advocate; thus, giving a good corporate image and reputation for businesses that support this App.

In addition, features that can create value to the customers such as the most active users, longest distance collected, top goal achiever, most weight lost, top challenger, top amount donated and notifications when charities need fundraising will be included where the users can adjust which notification they would like to turn on and off on their profile settings.

\section{Conclusion}


In conclusion, Spur promises the potential to transform the social and physical activities into gain competitive advantage for all actors that it can improve the overall quality of the society. The research idea of developing a social charity platform, Spur, is welcomed and might be the way forward for charity organizations, corporations that are looking into diversifying their CSR as well as for health enthusiast people that are trying to add more value to their daily routine. Spur with FinTech enabled will simplify lives and streamline all connecting entities and that is exactly where FinTech pursue and delivers.

\section{Acknowledgements}

This work was supported by Faculty Block Grant, Universiti Brunei Darussalam School of Business \& Economics No. UBD/RSCH/1.8/FICBF(b)/2020/006.

\section{References}

[1] Anshari, M., Alas, Y., \& Sulaiman, E. Smartphone Addictions and Nomophobia among Youth. Vulnerable Children \& Youth Studies, Taylor \& Francis. https://doi.org/10.1080/17450128.2019.1614709, (2019)

[2] Anshari, M., Almunawar, M.N., \& Masri, M., Hamdan, M. Digital Marketplace and FinTech to Support Agriculture Sustainability, Energy Procedia, 156C (2019) pp. 234238. Elsevier, (2019)

[3] Iriye, A. A Century of NGOs. Diplomatic History, 23(3), 421-435. doi:10.1111/01452096.00175, (1999)

[4] Martens, K. Voluntas: International Journal of Voluntary and Nonprofit Organizations, 13(3), 271-285. doi:10.1023/a:1020341526691, (2002)

[5] Amichai-Hamburger, Y. Potential and promise of online volunteering. Computers In Human Behavior,24(2), 544-562. doi: 10.1016/j.chb.2007.02.004, (2008)

[6] Anshari, M. Workforce Mapping of Fourth Industrial Revolution: Optimization to Identity. Journal of Physics: Conference Series, Vol. 1477 (072023). DOI:10.1088/1742-6596/1477/7/072023. IOP Publishing, (2020)

[7] Rajani, M. K., \& Chandio, M. S. Use of Internet and its effects on our Society. National Conference On Emerging Technologies, 157 - 161. Retrieved from http://www.szabist.edu.pk/Publications/Session\%20VIII\%20Paper\%20No\%202\%20( P\%2015 7-161).pdf, (2004)

[8] Anshari, M., Almunawar, M.N., \& Masri, M. Financial Technology and Disruptive Innovation in Business, International Journal of Asian Business and Information Management (IJABIM), Vol. 11 (4), IGI Global, (2020)

[9] Brian E. Perron, J. Information and Communication Technologies in Social Work. PubMed Central (PMC). Retrieved 3 April 2017, from https://www.ncbi.nlm.nih.gov/pmc/articles/PMC3117433/ (2011)

[10] Bargh JA, McKenna K, Fitzsimons GM. Can you see the real me? Activation and expression of the "true self" on the internet. Journal of Social Issues. 58(1):33-48, (2002)

[11] Chase, J. The Evolution of the Internet of Things. Retrieved October 22, 2018 , from http://www.ti.com/ww/en/connect_more/pdf/SWB001.pdf?DCMP=iot\&HQS=iot-nslwp, (2013) 
[12] Anshari, M., Almunawar, M. N., \& Masri, M. An Overview of Financial Technology in Indonesia. In M. Anshari, M. Almunawar, \& M. Masri (Eds.), Financial Technology and Disruptive Innovation in ASEAN (pp. 216-224). Hershey, PA: IGI Global. doi:10.4018/978-1-5225-9183-2.ch012, (2020)

[13] Rajak, W. Brunei is world's 4th highest in social media penetration. The Bruneian. Retrieved from https://www.thebruneian.news/brunei-is-worlds-4th-highest-in-socialmedia-penetration/, (2018)

[14] Othman, A. Surge in mobile phone, broadband penetration in Brunei. Borneo Bulletin. Retrieved from https://borneobulletin.com.bn/surge-mobile-phone-broadbandpenetration-brunei/, 2017)

[15] Authority for Info-communications Technology Industry of Brunei Darussalam. Brunei Darussalam Household ICT Survey Report 2016 [Ebook]. Bandar Seri Begawan.

https:/www.aiti.gov.bn/downloadables/Downloadables\%20Library/Household\%20I CT\%20S urvey\%202016\%20Report.pdf.pdf, (2016)

[16] Indexmundi, Brunei Demographics Profile 2018. Retrieved 1 Mac 2021 from https://www.indexmundi.com/brunei/demographics_profile.html, (2018)

[17] Azaraimy, A. (2018). Cardiovascular disease leading cause of death in Brunei. Retrieved from https://borneobulletin.com.bn/cardiovascular-disease-leading-causeof-death-in-brunei/, (2018)

[18] Shiroma, E., \& Lee, I. Physical Activity and Cardiovascular Health. Circulation, 122(7), 743-752. doi: 10.1161/circulationaha.109.914721, (2010)

[19] Mulyani, M.A., Razzaq, A., Sumardi, W.H., Anshari , M. Smartphone Adoption in Mobile Learning Scenario, International Conference on Information Management and Technology (ICIMTech), Bali, Indonesia, 2019. IEEE, (2019)

[20] Top 50 Countries with Highest Internet Penetration Rates - Country Literacy Rates. Retrieved from https://www.internetworldstats.com/top25.htm, (2018)

[21] Razzaq, A., Samiha, Y.T., \& Anshari, M. Smartphone Habits in Supporting Students Self-Efficacy at Higher Education, International Journal of Emerging Technologies in Learning, 13 (2), pp. 94-109. Kassel University Press, (2018)

[22] Ahad, A.D., Anshari, M., \& Razzaq, A. Domestication of Smartphones among Adolescents in Brunei Darussalam, Journal of Cyber Behavior, Psychology and Learning, Vol.7 (4), p.26-39. DOI: 10.4018/IJCBPL.2017100103. IGI Global, (2017) 